Tropical Journal of Pharmaceutical Research, April 2009; 8 (2): 105-109

(C) Pharmacotherapy Group,

Faculty of Pharmacy, University of Benin

Benin City, 300001 Nigeria.

All rights reserved.

Research Article

Available online at http://www.tjpr.org

\title{
Microstructural Observations on Nissl Substances in the Cerebellar Cortex of Adult Wistar Rats following Quinine Administration
}

\begin{abstract}
Adesina J Ajibade ${ }^{* 1}$, Olusola A Adeeyo ${ }^{1}$, David A Ofusori ${ }^{2}$, Thomas K Adenowo $^{3}$, Olufunto $O$ Ishola $^{4}$, Ebenezer A Ashamu ${ }^{1}$ and Spencer C Nwangwu ${ }^{5}$

${ }^{1}$ Department of Anatomy, Faculty of Basic Medical Sciences, Ladoke Akintola University of Technology, Ogbomoso; ${ }^{2}$ Department of Anatomy and Cell Biology, Faculty of Basic Medical Sciences, Obafemi Awolowo University, Ile-Ife; ${ }^{3}$ Department of Anatomy, Faculty of Basic Medical Sciences, Olabisi Onabanjo University, Ago-Iwoye; ${ }^{4}$ Department of Physiology, Faculty of Basic Medical Sciences, Ladoke Akintola University of Technology, Ogbomoso; and ${ }^{5}$ Department of Biochemistry, School of Basic Medical Sciences, Igbinedion University, Okada, Nigeria.
\end{abstract}

\begin{abstract}
Purpose: This study assessed some microstructural effects of quinine, commonly used in malaria chemotherapy, especially in chloroquine-resistant and cerebral malaria, on the Nissl substance in the cerebellar cortex of adult Wistar rats using microanatomical studies.

Methods: Twenty seven adult male Wistar rats, weighing between $150 \mathrm{~g}$ and $190 \mathrm{~g}$, were randomly separated into groups $A, B$ and $C(n=9)$. The rats in group $A$ served as the control and received intramuscular injection of physiological saline. Group $B$ rats were injected intramuscularly with liquid quinine, $16 \mathrm{mg} / \mathrm{kg}$ body weight as a start dose, followed by $8 \mathrm{mg} / \mathrm{kg}$ body weight 8 hourly for seven days. Group $C$ rats received the same treatment as group $B$ but were subjected to a withdrawal period of one week. Groups $A$ and $B$ rats were sacrificed at the end of the treatment while group $C$ rats were sacrificed at the end of one week. The cerebellum of each rat was removed and fixed in $10 \%$ formol saline for histological analysis.

Results: The findings showed that the Nissl substances in the cerebellar cortex in control rats stained more intensely and distinctly compared with the less intense stain and degenerated Niss/ substances in the treated rats.

Conclusion: The observed degenerative changes in the Niss/ substances in the cerebellar cortex of the treated rats may affect the synthesis of proteins in correlation with neuronal functions.
\end{abstract}

Keywords: Quinine, Nissl substances, Intensely stained, Cerebellar cortex, Degenerative changes.

${ }^{*}$ Corresponding author 


\section{Ajibade et al}

\section{Introduction}

Cerebral malaria remains a major cause of mortality and morbidity in many tropical areas of the world. In spite of improved therapy with ancillary support, mortality remains unacceptably high ${ }^{1}$.

Quinine is an effective chemotherapeutic agent for malaria, especially in chloroquine resistant and cerebral malaria ${ }^{2}$. It is, however, said to be more toxic than chloroquine ${ }^{3}$. The drug is extensively metabolized in the liver and only $10 \%$ is excreted unchanged in the urine ${ }^{3}$.

The cerebellum has three distinct layers and contains five major types of neurons ${ }^{4}$. The outermost layer is called the molecular layer, which contains few nerve cells with a finely punctate appearance in transverse section ${ }^{5}$. The middle layer also called the Purkinje cell layer, is composed of a single layer of Purkinje cell bodies. The deepest layer is the granular layer, which consists of densely packed granule cells ${ }^{6}$. The cerebellum, like the entire nervous system, is known to be affected by such substances as theobromide, theophylline and caffeine ${ }^{7,8}$. Cerebellar injuries have been reported to result from toxins, autoantibodies, structural lesion and inherited cerebellar degeneration ${ }^{9}$. In view of the reported irreversible toxic effects of quinine on the central nervous system, this work examines microstructural changes in the cerebellar cortex of rats following experimental quinine administration.

\section{Materials and Methods}

\section{Experimental animals}

Twenty seven mature male albino rats of Wistar strain, weighing between $150 \mathrm{~g}$ and $190 \mathrm{~g}$ were used in this study. The rats were fed daily with normal rat pellets purchased from Ladoke Feeds, Ibadan, Nigeria and water was given to the animals ad libitum. All the rats were carefully assessed, screened and confirmed to be healthy during the period of acclimatization. The animals were treated in accordance with the "Guide for the Care and Use of Laboratory Animals" prepared by the National Academy of Sciences and published by the National Institutes of Health ${ }^{10}$.

\section{Drug}

Quinine hydrochloride powder was procured from Sigma Chemical Company, London and an aqueous solution of the drug equivalent to $0.159 \% \mathrm{w} / \mathrm{v}$ of the quinine base was prepared. This was used as liquid quinine.

\section{Experimental design}

The rats were randomly assigned into three groups. Each group contained nine rats. Group A served as the control and received intramuscular injection of $1 \mathrm{ml}$ of physiological saline $(0.9 \% \mathrm{NaCl})$. Group B rats were injected intramuscularly with liquid quinine, 16 $\mathrm{mg} / \mathrm{kg}$ body weight, as a start dose followed by $8 \mathrm{mg} / \mathrm{kg}$ body weight 8 hourly for seven days. Group $\mathrm{C}$ rats received the same treatment regimen as group B. However, they were subjected to a post-treatment withdrawal period of one week to determine possible withdrawal effects on them before they were sacrificed.

\section{Histological procedure}

Histological study was carried out using the method of Carleton ${ }^{11}$. These procedures involved dehydration of the cerebellum tissues with graded ethanol concentrations $(50 \%$, $70 \%, 90 \%$ and $100 \%$, respectively), clearing in xylene, followed by infiltration in paraffin wax for $2 \mathrm{hr}$ at $56{ }^{\circ} \mathrm{C}$ and embedding in paraffin wax for $48 \mathrm{hr}$. Sections (5 $\mu \mathrm{m}$ thick) were then obtained, using a rotary microtome, subjected to thionine staining procedure and examined under a light microscope. Permanent photomicrographs of the observations were taken, using an Olympus Research Microscope (model BX51). 


\section{Results}

The cerebellar cortex of the control rats showed distinct and intensely stained Nissl substance in the cortical layers. The neurons in the three cortical layers appeared normal and were intensely stained (Figure $1 \mathrm{~A}$ ). The neurons were of various shapes and appeared distinct in all the cortical layers. The section of cerebellar cortex in quinine-treated rats (group B) revealed some degenerative changes, which made the neurons indistinct, particularly in the molecular layer. Similarly, the neurons in the molecular layer showed reduced staining intensity compared with the control rats. Some Purkinje cells also showed some degenerative changes with reduced staining intensity in the middle layer. Furthermore, the granule cells in the granular layer beneath the Punkinje cell layer revealed a reduced staining intensity (Figure 1B). Section of cerebellar cortex from group $C$ rats (withdrawal group) showed degenerative changes, which made the neurons indistinct with reduced staining intensity compared with the control rats. The Nissl substances in the Purkinje cells in the middle layer appeared degenerative with reduced staining intensity. The granule cells in the granular layer similarly revealed reduced staining intensity compared with the control (Figure 1C).

\section{Discussion}

Ribosomes, which are intensely basophilic owing to the presence of numerous phosphate groups of constituents, ribosomal ribonucleic acid acting as polyanious, react with such basic stains as methylene blue, toludine blue and haematoxylin. The sites in the cytoplasm that are rich in ribosomes stained intensely with these dyes. These basophilic regions are called Nissl bodies in neurons. The number of Nissl bodies varies according to neuronal types and functional state. They are particularly abundant in large nerve cells such as the motor neurons.

The observed neuronal degeneration in association with loss of Nissl bodies with reduced staining intensity of the Nissl substances in the cerebellar cortex of the treated rats in the present study agrees with the findings of Ajibade et $\mathrm{al}^{12}$. Degenerative and vacuolar changes were observed in many large brain stem neurons in mice that were treated with trimethyl chloride; these neurons acquired a chromatolytic character with eccentric nuclei and loss of Nissl substances, which became progressive when studied with electron microscopy ${ }^{13}$. Fatigue, from over exertion, produced in the brain cells similar changes to those produced by fear, these changes being proportional to the amount of exertion, resulted in exhaustion, and consequently, enormous reduction in Nissl substance $^{14}$. Similarly, the animals showed neuronal and secondary axonal damage that was most prominent in the cerebellar roof, pontine and vestibular nuclei. The affected neurons showed loss of Nissl substance and shrinkage of the nucleus in dog following intramuscular administration of artemether ${ }^{15}$.

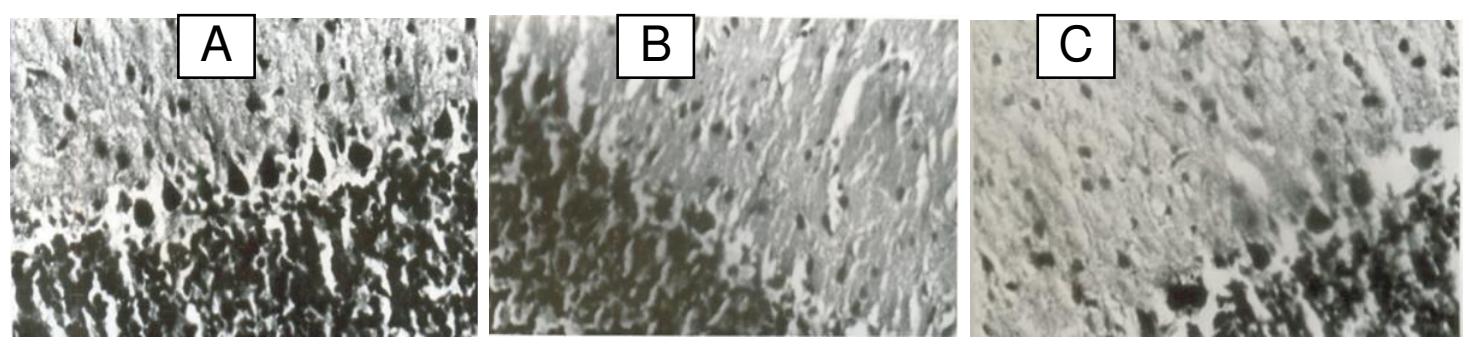

Figure 1: Normal and intensely stained Nissl substances in the cerebellar cortical layers (A), less intensely stained and degenerating Nissl substances in the cerebellar cortical layers (B), and less intensely stained and degenerating Nissl substances in the cerebellar cortical layers (C). (X400 Thionine stain). 
Injury to axons or neuronal exhaustion, resulting from strong or prolonged stimuli, causes a reduction in the number of Nissl bodies. This alteration, which is called chromatolysis, occurs simultaneously with nuclear migration to the periphery of the perikaryon $^{16}$, and consequently the RNA level is reduced. Chemical and toxic substances affect the Nissl substance thereby influencing their metabolic activity ${ }^{17}$. Similarly, Martin et $\mathrm{al}^{18}$ reported that neuronal degeneration causes a reduction in Nissl bodies. Neuronal degeneration in quinine-treated rats has already been reported ${ }^{12}$.

The neurotoxic effect of quinine in the present study might have caused neuronal degeneration with a reduction in Nissl bodies; consequently, reduced staining intensity of the Nissl substance in the cerebellar cortex of the treated rats may be due to neuronal pathology, following the neurotoxic effect of quinine. It is possible that quinine had an irreversible effect on the Nissl substances in the cortical layers of the cerebellar cortex, bringing about such microstructural changes in the neurons which manifested as degeneration and loss of Nissl substances with reduced staining intensity of the Nissl substances in the cerebellar cortex of the quinine-treated rats. Degeneration and loss of Nissl substances may consequently affect the synthesis of both structural protein and protein for transport in correlation with neuronal functions. If our findings are extrapolated to man, they suggest that indiscriminate use of quinine may hamper proper coordination of muscular activities and maintenance of posture and equilibrium but this would need to be investigated.

\section{Conclusion}

Administration of an initial dose of $16 \mathrm{mg} / \mathrm{kg}$ body weight and a further $8 \mathrm{mg} / \mathrm{kg}$ body weight of quinine to adult Wistar rats for a period of seven days resulted in neuronal degeneration and loss of Nissl substances as evidenced by reduced staining intensity in the Nissl substances of the cerebellar cortex in treated rats. This implies that quinine adversely affected the Nissl substances of the cerebellar cortical layers of the rat model and by extension, may hamper proper coordination of muscular activities and maintenance of posture and equilibrium.

\section{Acknowledgment}

The authors wish to express their profound gratitude to the technical staff of the Anatomy and Cell Biology Department, Obafemi Awolowo University, Nigeria, for their support in the execution of this work.

\section{References}

1. Mohanty S, Mishra SK, Satpathy SK, Mohanty D, Mohapatra DN. Comparison of intramuscular arteether and intravenous quinine for the treatment of cerebral malarial. J Indian Acad Chem Med 2000; 5 (2): 119-123.

2. White NJ, Warrel DA. Chemical management of chloroquine-resistant plasmodium falciparum Malaria in South-east Asia. Trop. Doct 1983; 13:153-158.

3. Kakkilaya BS. Quinine, Kakkilaya's malaria website @malaria site. Com 2002; pp. 1-2. www.malariasite.com/malaria/malaria_contents. htm Accessed 12 July, 2007.

4. Chusid JG. The cerebellum In: Correlative neuroanatomy and functional neurology. $17^{\text {th }}$ Ed, Lange Medical Publications, Los Altos, 1979; pp 39 and 171.

5. Abdi FB, Pollard J, Wilkison JM. Placental transfer and foetal disposition of caffeine and its metabolites in twenty day pregnant rats. A function of dose. Xenobiotics 1996; 23: 449456.

6. West JR. The cerebellum. In: Neuroscience in medicine. Conn PN (ed) JB Lippincott Company, Philadelphia, USA, 1995; Chap 12, pp 214-224.

7. Kimel CA, Kimel GL, White C, Grasto TE, Young JF, Nelson GJ. Blood flow changes and conceptional development in pregnant rats in response to caffeine. Funct Appl Toxicol 1984; 40: 240-447.

8. Hain TC, Zee DS, Maria B. Tilt-suppression of the vestibulo-ocular reflex in patients with cerebellar lesions. Acta Otolaryngology (Stockholm) 1988; 105:13-20.

9. Snow RW, Guerra CA, Noor AM, Myint HY and Hay SI. The global distribution of clinical episodes of Plasmodium falciparum malaria. Nature 2005; 434 (7030): 214-217.

10. National Institute of Health Guide for the Care and Use of Laboratory Animals: DHEW Publication 


\section{Ajibade et al}

(NIH), revised, Office of Science and Health Reports, DRR/NIH, Bethesda, USA, 1985.

11. Carleton H. Carleton's histological technique. Oxford University Press, $4^{\text {th }}$ Ed 1967; pp. 33-280.

12. Ajibade AJ, Adenowo TK, Fegemilehin ME, CaxtonMartins EA, Omotoso EO. Some histological observations on the cerebellar cortex of adult wistar rats following quinine administration. Science Focus 2006; 11 (2): 97-100.

13. Change LW, Tiemeyer TM, Wenger GR, McMillian DE. Neuropathology of trimethyl chloride intoxication. Three changes in the brain stem neurons. Eviron Res. 1983; 30 (2): 399-411.

14. Waters CM, Wakinshaw G, Moser B and Mitchell IJ: Death of Neurons in the neonatal rodent globus pallidus occurs as a mechanism of apoptosis. Neuroscience 1994; 63: 881-894.

15. Classen W, Altmann B, Gretener P, Souppart C, Skelton-Stroud P, Krinke G Abstract presented at the 7th International Neurotoxicology Association Meeting, Leicester, United Kingdom, International Neurotoxicology Association INAT Abs 1999; pp 1-47

16. Luis E, Vergés JA, Flores F. Effect of disordered concentrated nonmagnetic impurities on the periodic Anderson Hamiltonian in one dimension. Phys. Rev. B; 1986; 34: 6415 6419.

17. Davis RL, Robertson DM. Textbook of neuropathology, $2^{\text {nd }}$ edition, Williams and Wilkins, London, 1991; pp. 5-7.

18. Martin LJ, Al-Abdulla FE, Portera CC. Neurodegeneration inexitoxicity, global cerebral ischaemia and target deprivation. A perspective on the contribution of apoptosis and necrosis. Brain Res Bull, 1978; 46(4): 281-309. 